\title{
CORRIGENDUM
}

to

\section{"SPATIAL DIFFERENCES IN FRESH VEGETABLE SPENDING: A CASE STUDY IN GUILFORD COUNTY, NORTH CAROLINA"}

by H. Miao, L. Hashemi-Beni, T. Mulrooney, L. A. Kurkalova, C. L. Liang, M. Jha, and G. Monty,

Int. Arch. Photogramm. Remote Sens. Spatial Inf. Sci., XLIV-M-2-2020, 73-77,

https://doi.org/10.5194/isprs-archives-XLIV-M-2-2020-73-2020, 2020.

The first author found that the current affiliation at the time of publication was not included in the version sent to the editors and the publisher. Please find below the amended list of affiliations/contact data:

Haoran Miao $^{1 *}$, Leila Hashemi-Beni ${ }^{1}$, Timothy Mulrooney ${ }^{2}$, Lyubov A. Kurkalova ${ }^{1}$, Chyi-Lyi Liang ${ }^{1}$, Manoj Jha ${ }^{1}$, Gregory Monty ${ }^{1}$

${ }^{1}$ North Carolina A\&T State University, USA

${ }^{2}$ North Carolina Central University, USA

${ }^{*}$ Corresponding author. Current affiliation: Nanjing University of Finance and Economics, Nanjing, China haoran_miao@my.uri.edu

The authors apologize for the inconvenience.

10 December 2020 